\title{
OS FIOS QUE MOVIAM Michel de Montaigne
}

The strings that moved Michel de Montaigne

\section{Claudia Borges de Faveri}

ORCID 0000-0001-5305-3227

Universidade Federal de Santa Catarina Florianópolis, SC, Brasil

JOUANNA, Arlette. Montaigne. Paris: Gallimard, 2017, 460p.

Nos últimos dias de 2018, uma notícia atraiu os olhares do mundo intelectual e jornalístico do mundo todo. Tudo indicava que, finalmente, após quase 500 anos, os restos mortais de Michel de Montaigne teriam sido descobertos no subsolo do Museu da Aquitânia, em Bordeaux, oeste da França. As investigaçóes continuam e ainda não se tem certeza se o que se pôde ver - um caixão em madeira, ossos humanos e uma placa em bronze dourado com o nome de Michel de Montaigne -, através de dois pequenos orifícios feitos nas grossas paredes do subsolo, tem de fato alguma relação com o filósofo e escritor renascentista. Tudo leva a crer que, desde sua morte em 1592, os restos mortais de Montaigne tenham errado de sepultura em sepultura até chegar, não se sabe ainda quando, a este museu em Bordeaux. Bordeaux, que Montaigne administrou entre 1581 e 1585 por dois mandatos consecutivos, e que, graças à sua capacidade de negociação e moderação, foi por ele mantida a salvo das pertubaçôes e desordens das guerras de religiâo que devastavam então a França.

Por que tanto barulho a respeito dos restos mortais de um filósofo e escritor que, sem que se negue sua importância, viveu há mais de quatro séculos? A resposta talvez seja simples, embora pareça impertinente: é porque é Montaigne. Resposta que aqui parodia enviesadamente a famosa fórmula do próprio, em seu famoso ensaio 27 do livro I, 'Da Amizade', ao tentar explicar sua ligação com Etienne de La Boétie: "[...] porque era ele, porque era eu" . Montaigne, cuja obra maior, quase única, na verdade - Os Ensaios (1580-1582) -, vem sendo traduzida e reeditada mundo afora há quatro séculos. Montaigne, que parece obstinar-se em se manter atual. Suas primeiras

1 "Si on insiste pour me faire dire pourquoi je l'aimais, je sens que cela ne peut s'exprimer qu'en répondant: parce que c'était lui, parce que c'était moi” (MONTAIGNE, 2008, p. 276). Todas as traduçóes ao português constantes desta resenha são de minha autoria. 
traduçóes no Brasil datam do início do século XX, mas na Inglaterra, por exemplo, a primeira tradução é de 1603, realizada por John Florio (15531625), escritor, lexicógrafo e professor inglês, poucos anos após a edição original em francês.

Montaigne influenciou todos os grandes nomes depois dele, de Shakespeare a Nietzsche, de Bacon a Pascal, e suscita, ainda hoje, importantes pesquisas sobretudo nas áreas da Filosofia e da Educação. No que concerne ao Brasil, Sérgio Cardoso (2017, p. 19) ressalta que nosso país está certamente entre aqueles que mais produziram trabalhos acadêmicos sobre o autor renascentista na área da Filosofia nos últimos vinte anos. De Machado a Oswald de Andrade, passando por Ciro dos Anjos, a influência de Montaigne em nossas letras é também inegável.

Essa vitalidade do autor de Os Ensaios revela-se não só pelas constantes reediçóes e retraduçóes de sua obra maior, mas curiosamente também pelo crescente número de biografias a seu respeito, das mais variadas faturas, que têm vindo à luz nos últimos anos. Algumas dessas, surpreendentemente, tornaram-se campeãs de venda, como é o caso de duas delas, a saber: Como Viver, de Sarah Bakewell, e Uma temporada com Montaigne, de Antoine Compagnon. Ambas já lançadas no Brasil, respectivamente, pela Objetiva, em 2012, com tradução de Clóvis Marques, e pela WMF Martins Fontes, em 2015, com tradução de Rosemary Abílio.

Restringindo-nos táo somente ao gênero biografia e ao período compreendido entre 2000 e 2019, no Brasil, além dessas duas citadas acima, temos ainda o Montaigne de Peter Burke, lançado pela Editora Loyola em 2006, com tradução de Jaimir Conte, e, finalmente, em 2016, o Montaigne do filósofo marroquino radicado na França Ali Benmakhlouf, com tradução de Guilherme João de Freitas Teixeira, pela Estação Liberdade. Se abrirmos ainda mais o leque, considerando estudos de cunho filosófico, o leitor brasileiro pode ter acesso a uma fortuna crítica razoável sobre o filósofo renascentista ${ }^{2}$.

Mas, voltando às biografias, a mais recente delas, ainda sem tradução ao português, que também tem por título Montaigne, veio à luz em fins de 2017, publicada pela Gallimard na coleção NRF Biographies. São 460 páginas nas quais a autora Arlette Jouanna, professora emérita da Universidade Paul Valéry de Montpellier e especialista em história social e política do século XVI francês, tenta trazer a seu leitor um retrato acurado do cultuado autor dos Ensaios. Mas o que traz de novo mais uma biografia de Montaigne em um universo em que as biografias existentes já conquistaram inúmeros leitores em todo o mundo? A própria autora náo deixa de citar ao menos seis outras que lhe precedem, sublinhando a vocaçáo e utilidade de cada uma delas. $\mathrm{O}$

2 Tais informaçôes encontram-se esparsas. Para remediar tal situação, estamos preparando uma bibliografia comentada dos estudos de Montaigne no Brasil, a ser publicada em breve. 
fato é que, paradoxalmente, a vida de Montaigne é muito pouco conhecida, muito do que se sabe dele é por sua própria pena, mormente em seus Ensaios.

Para Jouanna, compreender e conhecer Montaigne exige ultrapassar o mito, e enraizá-lo, na medida do possível, em seu tempo. Destarte, ela não se contenta em repetir ou pouco acrescentar à imensa literatura já existente sobre o filósofo renascentista. Com seu olhar de especialista em século XVI, o que ela nos oferece é uma visão bem particular, do ponto de vista historiográfico, ao mesmo tempo em que se revela uma leitora apaixonada dos Ensaios, sem que por isso deixe de ser consequente.

A Introdução fornece-nos o plano do livro, que se desenrola ao longo de doze capítulos e revela as inúmeras facetas de Montaigne. A autora faz questáo de nos lembrar (p. 17) o que o próprio Montaigne escreve em 'Da Vaidade', Ensaio 9 do Livro III: "eu voltaria de bom grado do outro mundo para desmentir quem me pintasse diferente do que sou, mesmo que fosse para me louvar" 3 . Parece levar a sério tal aviso ao enfatizar que são raras as fontes dos arquivos históricos acessíveis ao pesquisador. É com grande prudência, portanto, que avança hipóteses, atendo-se em grande medida ao estritamente factual. Nesse sentido, é preciso renunciar, afirma, a um conhecimento exaustivo do que viveu Montaigne. Suas fontes, tanto as manuscritas quanto as já publicadas, são cuidadosamente repertoriadas ao fim do livro (p. 421), assim como as obras de e sobre Montaigne que utilizou em sua pesquisa.

Ainda na Introdução, Jouanna escolhe começar sua narrativa em 1571, ano em que Montaigne completa 38 anos, data emblemática de sua famosa retirada das coisas mundanas. Segundo a autora, o momento fundador do Montaigne que passará à posteridade. E é por esse momento, a entrada no processo de escrita dos Ensaios, que o relato de Jouanna entra na vida de seu autor, momento que ela descreve assim (JOUANNA, 2017, p. 13):

Trata-se aqui, com efeito, de uma ruptura com relação aos ideais mundanos comuns, de uma reviravolta que o faz verdadeiramente nascer para si mesmo. Tudo o que aconteceu antes foi táo somente a lenta liberação do condicionamento familiar e social imposto por seu meio, de pessoas importantes socialmente e que haviam ascendido à nobreza há pouco tempo, e depois a progressiva liberação das servidôes de uma carreira que ele não havia escolhido. ${ }^{4}$

3 "Je reviendrais volontiers de l'autre monde pour démentir celui qui me formerait autre que je n'étais, fût-ce pour m'honorer" (MONTAIGNE, 2004, apud JOUANNA, 2017, p. 17).

4 "Il s'agit bien là, en effet, d'une rupture avec les idéaux mondains ordinaires, d'un retournement qui le fait naître véritablement à lui-même. Tout ce qui s'est passé auparavant n’aura été que la lente libération du conditionnement familial et social imposé par son milieu de notables tout juste agrégés à la noblesse, puis le progressif arrachement aux servitudes d'une carrière de magistrat qu'il n'a pas choisie" (JOUANNA, 2017, p. 13). 
Em seguida, o primeiro capítulo que a autora escolheu chamar de (p. 21) "Um lento nascimento de si mesmo", aborda os 38 primeiros anos de Montaigne, de 1533 a 1571, antes que começasse a aventura de escrita de seus ensaios. Aqui são apresentados aspectos e fatos da vida de Montaigne relacionados ao condicionamento social e familiar, tais como o enobrecimento da família, o apego ao título e à terra - sendo, no século XVI, esta última a garantia do primeiro -, a infância, as relaçóes familiares e os anos de formaçáo.

Os capítulos se sucedem seguindo uma organização temático-cronológica que apresenta as várias faces de Montaigne, dentre as quais a de jurista, ou funcionário do parlamento, a de pensador inquieto, cujo encontro com La Boétie e com os canibais do Brasil alimenta uma reflexão surpreendentemente moderna sobre as éticas da diferença e as liberdades civis, e a de senhor de terras, vinhas e campos, às voltas com as vicissitudes próprias a um nobre do século XVI. Mas ele é também um ator político importante no contexto de uma França devastada pelas guerras de religião (1562-1598) que opóem católicos a protestantes.

O leitor de Jouanna encontra também o Montaigne viajante, autor de um diário de viagem pela Alemanha, Suíça e Itália (ainda sem tradução ao português), e o prefeito de Bordeaux duas vezes eleito (1581-1585), que consegue manter a cidade a salvo da guerra, mas não da peste que vitima, de junho a dezembro de 1585, algo em torno de quatorze mil pessoas. Montaigne é também o estudioso, o escritor, que dedica a segunda metade de sua vida, a partir de 1571, a ler e escrever e, por fim, em 1580, a publicar seus Ensaios. Conhecendo a notoriedade em vida como escritor e pensador, ele é um autor dedicado que vai corrigir e alterar os três volumes de sua obra (pouco mais de 1000 páginas) até sua morte em 1593. Por fim, a imagem que talvez seja a mais conhecida do renascentista: o pensador retirado em sua torre-biblioteca circular, cercado de livros da Antiguidade e de máximas em latim que ele mandou pintar nas vigas do teto.

Como historiadora, especialista do período renascentista, é um homem do Renascimento que Jouanna descreve; as passagens nas quais a autora mais destaca - capítulos VI, VIII, IX e X - são justamente aquelas relacionadas a seu campo de especialidade. Assim, o leitor pode compreender Montaigne, e também sua obra, a partir da explicitação de aspectos como os laços de fidelidade que uniam necessariamente os membros da classe nobre, laços esses complexificados pelas guerras de religião. É também possível apreciar a posição delicada de Montaigne como católico moderado em um contexto de radicalizaçóes. E ainda seu amor à liberdade, muito embora apegado à nobreza há pouco tempo conquistada por seus ancestrais. São aspectos que, sob o pano de fundo renascentista que Jouanna tão bem conhece, contribuem para uma melhor compreensão da obra como expressão de um pensamento político 
dividido entre humanismo, dever de fidelidade e descrença na razoabilidade dos homens. É um olhar novo, assim, que a historiadora propicia ao leitor dos Ensaios.

É preciso dizer, no entanto, que o leitor que busque um maior aprofundamento dos aspectos propriamente literários e filosóficos da vida de Montaigne, e suas relaçóes com os grandes nomes do humanismo, corre o risco de se decepcionar, pois tais pontos não estấo no centro das preocupaçôes de Jouanna. Ocupa-a preferencialmente aspectos historiográficos, sobretudo no que concerne à gênese do Estado moderno. As várias faces de Montaigne que nos apresenta Jouanna dialogam, portanto, muito mais com a historiografia do que com a literatura ou a filosofia. E isso pode ser visto como um defeito, ou uma lacuna, por aqueles que busquem o Montaigne escritor, imbuído de cultura da Antiguidade, leitor disciplinado e interlocutor dos grandes nomes da época.

Montaigne, segundo Jouanna, não se deixa reduzir a definiçóes simplistas. Seu pensamento sempre mutante, variegado, multifacetado, presta-se a múltiplas abordagens e análises. Ela sublinha ademais a influência que ele exerce ainda em nossos dias. Para a historiadora, não só como especialista, mas também como leitora apaixonada dos Ensaios, a explicação para essa inusitada permanência reside no que une o autor renascentista ao homem contemporâneo. Como nós, ele viveu em tempos difíceis, de futuro incerto, marcados pelo enfraquecimento das crenças, a perda de referências, a contestação das estruturas políticas e a violência dos radicalismos. Montaigne nos acena, segundo a autora, com uma possibilidade de sobreviver a todas as incertezas com dignidade interior, fazendo prevalecer a ironia, e mesmo o riso, sobre a angústia. Seus Ensaios são o palco onde evolui um homem que tenta ver claro em si e em seu entorno, com lucidez e ironia desconcertantes. 
Referências

CARDOSO, Sérgio. Montaigne filósofo. Cult, n. 221, São Paulo, p. 18-19, 2017.

JOUANNA, Arlette. Montaigne. Paris: Gallimard, 2017.

MONTAIGNE, Michel de. Essais I. Paris: Pernon Éditions, 2008.

Claudia Borges de Faveri. Professora titular do Departamento de Língua e Literatura Estrangeiras da Universidade Federal de Santa Catarina, onde atua na área de língua e literaturas de expressão francesa e tradução literária. É doutora em Ciências da Linguagem pela Universidade de Nice-Sophia Antipolis, França. Em 2018-2019, realizou seu segundo pós-doutorado na Universidade Federal do Rio de Janeiro, com pesquisa dedicada à recepção, permanência e tradução da obra de Michel de Montaigne no Brasil.

E-mail: cbfaveri@gmail.com 